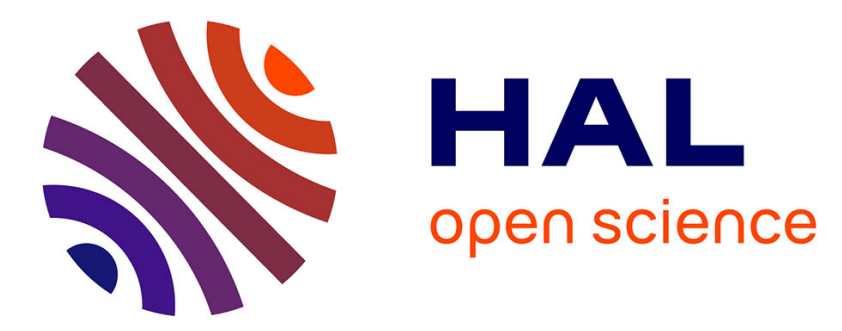

\title{
Assembly Sequence Influence on Geometric Deviations of Compliant Parts
}

\author{
Mathieu Mounaud, François Thiebaut, Pierre Bourdet, Hugo Falgarone, \\ Nicolas Chevassus
}

\section{- To cite this version: \\ Mathieu Mounaud, François Thiebaut, Pierre Bourdet, Hugo Falgarone, Nicolas Chevassus. Assembly Sequence Influence on Geometric Deviations of Compliant Parts. International Journal of Production Research, 2010, pp.1. 10.1080/00207540903460240 . hal-00564093}

\section{HAL Id: hal-00564093 https://hal.science/hal-00564093}

Submitted on 8 Feb 2011

HAL is a multi-disciplinary open access archive for the deposit and dissemination of scientific research documents, whether they are published or not. The documents may come from teaching and research institutions in France or abroad, or from public or private research centers.
L'archive ouverte pluridisciplinaire HAL, est destinée au dépôt et à la diffusion de documents scientifiques de niveau recherche, publiés ou non, émanant des établissements d'enseignement et de recherche français ou étrangers, des laboratoires publics ou privés. 


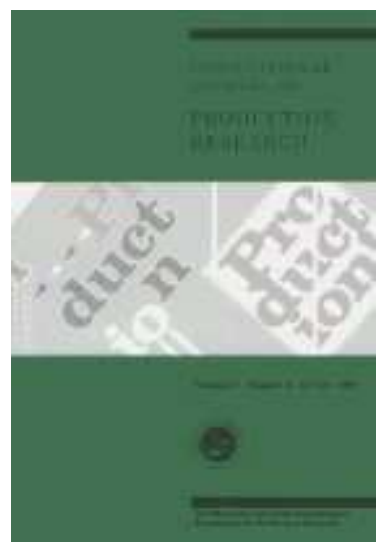

\section{Assembly Sequence Influence on Geometric Deviations of Compliant Parts}

\begin{tabular}{|r|l|}
\hline Journal: & International Journal of Production Research \\
\hline Manuscript ID: & TPRS-2009-IJPR-0506 \\
\hline Manuscript Type: & Original Manuscript \\
\hline Author: & 01-Jun-2009 \\
\hline Complete List of Authors: & $\begin{array}{l}\text { Mounaud, Mathieu; LURPA } \\
\text { Thiebaut, François; LURPA-ENS Cachan } \\
\text { Bourdet, Pierr; LURPA-ENS Cachan } \\
\text { Falgarone, Hugo; EADS-IW } \\
\text { Chevassus, Nicolas; EADS-IW }\end{array}$ \\
\hline Keywords: & TOLERANCE ANALYSIS, ASSEMBLY PLANNING, SEQUENCING \\
\hline Keywords (user): & \\
\hline
\end{tabular}

\section{今scholarONE" \\ Manuscript Central}




\title{
Assembly Sequence Influence on Geometric Deviations Propagation of Compliant Parts
}

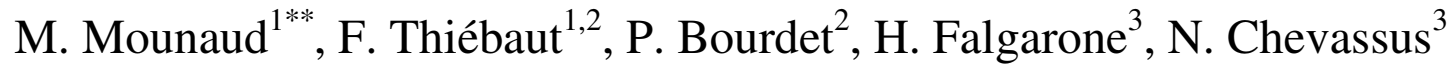 \\ ${ }^{1}$ LURPA, ENS de Cachan, 61, Avenue du Président Wilson, 94235 Cachan Cedex, \\ France \\ ${ }^{2}$ IUT Cachan, 9, Avenue de la division Leclerc, 94235 Cachan Cedex, France \\ ${ }^{3}$ EADS-IW, 12, rue Pasteur, 92150 Suresnes, France
}

(Received 01 June 2009;)

\begin{abstract}
This paper presents a non-rigid part variation simulation method for fulfilling functionnal requirements on compliant assemblies. This method is based on the propagation of different geometrical deviations (manufacturing and assembly process defects) using the Method of Influence Coefficient. Tolerance analysis of compliant assemblies is also achieved very early in the design stage. As a consequence, designers and manufacturing engineers can efficiently analyse the assembly design principles both in terms of installed stresses and geometric variation clearance. They can also set optimised' sequences that enable to get rid of geometric variations.
\end{abstract}

Keywords: Tolerancing Analysis, compliant parts, assembly sequencing

\section{Introduction}

To reduce energy consumption, automotive and aeronautics industry are concerned with decreasing the weight of their assemblies while using more and more systems to improve their products -avionics, electronics, hydraulics or mechanical systems, for instance. The important developments in computer engineering in the last three decades allow these industries to model more and more components during the design stage. The complexity may be defined in terms of material or mechanical behaviour, geometry. It also involves manufacturing overconstrained assemblies taking into account part compliance.

The reduction in time development leads these industries to simulate the behaviour of their assembly as accurately as possible and at the earliest stage, in order to minimize the need for physical tests and to improve their producibility. A way to achieve this aim is the use of variation simulation tools as soon as possible.

\footnotetext{
* Corresponding Author. Email : mounaud@lurpa.ens-cachan.fr
} 
In early design, the nominal dimensions of parts are decided and tolerances and locating schemes are assigned. Assemblies with such parts have to respect some functional requirements like geometric clearance or installed stresses in the assemblies' joints. At any time, it is important to make sure that the functional requirements of a complex assembly are satisfied. Söderberg [1] explains that variation in a geometrical key characteristic of an assembly depends on three different sources: component variation, assembly variation and design concept as shown in Figure 1. Mechanisms in automotive or aircraft industries are composed of compliant parts with deviations from nominal shapes. Moreover such parts may be jointed together with an important number of joints which overconstrain the considered assembly. In this context, the industrial need for variation simulation tools used in the design stage increases quickly, while the development and pre-production time decreases.

Please Insert Figure 1

There are different ways to manufacture an over-constrained assembly of components whose geometry has defects:

- Components should have restrictive tolerances. This implies important costs, which makes the industry less competitive.

- Some kinematic adjustments between parts may be used to compensate for assembly variation. Functional requirements may not be expected.

- Components may be compliant to compensate for parts' defects.

- Finding the best equilibrium between the last two points.

To help designers analyze their products, it is thus important to provide them with tools to perform the best and fastest choices; more particularly to predict how the design and set of tolerances they assign to assembly compliant parts affect the product's functional requirements. 


\section{Scope of the paper}

This paper presents a method based on different existing approaches to analyze an assembly composed of compliant parts. Used in the design stage, the proposed method allows engineers to verify if functional requirements of final assembly are fulfilled. The proposed method relies on two major axes which are tolerance analysis and compliant assembly variation.

After a description of recent advances, the simulation tools that are used are developed. To illustrate this theory, an aeronautic hydraulic system assembly is presented in section four as a case study. The last section discusses the results and concludes the paper.

\section{Literature review}

Over the past years, many different approaches to Tolerance analysis and Compliant Assembly Variation have been developed.

Many researchers have worked on tolerance analysis and developed different models, Wirtz (1998) studies, for example, vectorial tolerancing whereas Pillet et al. (2005) worked on inertial tolerancing. Torsor and Jacobian approaches were respectively developed by Ballot et al. (1995) and Laperriere et al. (2002), just to name a few. Laperriere and Kabore (2001) have already worked on tolerance synthesis with Monte Carlo simulation, but most of these works deal with tolerance analysis of rigid-body components, which is far from the exposed context.

Tolerance analysis for compliant parts consists in predicting the amount of misalignment that will occur between parts, but also enables to predict the amount of deformation of parts and stresses in joints. Many research works have focused on predicting dimensional variation on sheet metal assembly. Most of the developed methods rely on Finite Element Analysis (FEA). Chang and Gossard (1997) simulated 
the assembly and measurement processes with part stiffness matrix to find the final variation of an assembly. Liu and $\mathrm{Hu}$ (1997) proposed a model to analyze the effect of part geometrical deviations and assembly springback on assembly variation. The method based on sensitivity matrix, called method of influence coefficient, combines FEA and Monte Carlo simulation to reduce computational costs. Ceglarek and Shi (1997) presented a Beam-based model for tolerance analysis for sheet metal assemblies. Merkley (1998) proposed a tolerance analysis of compliant parts which accounts for the part covariance in conjunction with the part stiffness matrix. Cid et al. (2005) established an extension of 3D link chains to provide symbolic equations of the assembly by integration of compliance and actual deviation from the nominal shape of the considered part. Breteau et al. (2007) developed this approach for the measurement of compliant parts. Most of these works, based on the study of one compliant part, have been extended to mechanisms composed of several parts and/or to the integration of different parameters influencing assembly variation.

Hu et al. (2006) summarized recent developments in simulation models for compliant assemblies and presented different applications. Based on assembly state space models and multi-station levels for assembly variation analysis, Camelio et al. (2003) developed these applications for variation analysis, robust design, tolerance allocation and variation reduction. The state space model has been extended by Loose et al. (2009) with the development of an analytical derivation to describe features deviations controlled by GD\&T characteristics. For tolerance analysis some aspects such as assembly sequence, contact modelling, we refer to Dahlström et al. (2005), and fixture layout, referring to Huang et al. (2007), need to be incorporated to find a correlation between simulated variations and actual ones. Söderberg et al. (2007) presented a tool for non-rigid variation simulation and visualization based on 
sensitivity matrix and more particularly on the unit influence coefficient method. This paper proposes to extend this approach by taking into account relevant aspects exposed before such as assembly sequence, fixture defects and compliance, manufacturing variations in order to check if functional requirements of a compliant hydraulic assembly, we refer to Mounaud et al. (2007), are satisfied. Wei (2001) used a similar approach to the one proposed to predict the fulfilment of functional requirements of such assemblies by taking into account geometrical variations in tubes and in structures in order to evaluate the cost of different designs. But the proposed models are restricted to tube compliance with no influence of the assembly sequence.

\section{Description of the proposed method}

Part compliance enables assembly but it also causes considerable variations that influence the final geometry of the assembly. As compliant parts may be linked to others parts (compliant or not) with important number of joints it over-constrains the considered mechanism.

To be functional, assemblies of compliant parts need to fulfil some functional requirements (see equations 1 and 2) which are usually residual stresses " $F_{i}$ " of the assembly in each joint "i" and geometrical requirements " $\mathrm{U}_{\mathrm{i}}$ " on specific points of the assembly.

$$
\begin{aligned}
& F_{i}<F_{\text {max }} \\
& U_{i}<U_{\text {max }}
\end{aligned}
$$

To predict the fulfilment of the above functional requirements the proposed method is carried out according to the seven following steps detailed in the current section:

(1) Definition of each part's deviations.

(2) Definition of the mechanical behaviour of each part. 
(3) Definition of the mechanical behaviour of the assembly

(4) Calculation of the Influence matrix based on the unit displacement method and part stiffness matrix from Finite Element Analysis

(5) Identification of the most robust fixturing scheme for part localization.

(6) Simulation of an assembly sequence

(7) Results

\section{Actual Geometry of components}

Considering Tolerance Analysis and assembly simulation, the actual geometry of parts is supposed to be known thanks to admissible geometries described through geometric specifications or indirectly by the way of manufacturing parameters. Whatever the definition of admissible geometry, a representative set of geometry instances is supposed to be known for each part of the assembly.

Let us suppose a frame is attached to each component of the assembly. For each point $\mathrm{Ci}$ of the nominal component, the manufacturing deviation $\mathrm{d}_{\mathrm{M}}(\mathrm{Ci})$ from the nominal model to the component is known and expressed relatively to the component frame. The actual position of a point $\mathbb{C}_{i}$ of the component is known by the equation 3:

$$
\epsilon_{i}=C_{i}+d_{M}\left(C_{i}\right)
$$

\section{Definition of mechanical behaviour of each component}

Tolerance analysis is applied on assemblies that mix rigid components and compliant components.

- Considering compliant components, geometric and mechanical behaviour are linked through a rigidity matrix since the following hypotheses are used:

- the deformation of the component remains linear,

- material behaviour is isotropic,

- small displacements are considered.

Let the deformation of the component be expressed relatively to the associated frame. Let $\mathrm{Ci}$ be a nominal point of a component $\mathrm{C}$, the position of the point that results in a small displacement of the component frame and of the component deformation is given by the equation 4 . 


$$
C_{i}^{*}=\left[\begin{array}{rrrr} 
& \underline{\underline{R}} & & T \\
0 & 0 & 0 & 1
\end{array}\right]\left[C_{i}\right]+U\left(C_{i}\right)
$$

where $\underline{\underline{\mathrm{R}}}$ represents the small rotation of the frame, $\mathrm{T}$ represents the translation of the origin of the frame and $\mathrm{U}$ represents the displacement of the $\mathrm{Ci}$ point due to the component deformation (as shown in figure 2).

Please insert Figure 2

The displacement of the $\mathrm{Ci}$ point due to the component deformation is implicitly known by the linear relations between exterior mechanical solicitations $\mathrm{F}$ and displacements $\mathrm{U}$ :

$$
F=\underline{\underline{K}} . U
$$

where $\underline{\underline{\mathrm{K}}}$ is the matrix rigidity of the component.

- Considering rigid components, the geometric behaviour is defined through screw theory as far as geometry is concerned and static as far as mechanical behaviour is concerned.

Let $\mathrm{Ci}$ be a nominal point of a component $\mathrm{C}$, the position of the point that results in a small displacement $\mathrm{Ci}^{*}$ of the component frame is given by the equation 6

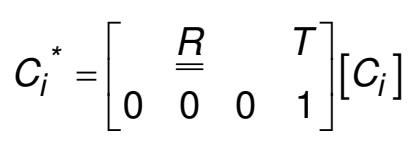

where $\underline{\underline{\mathrm{R}}}$ represents the small rotation of the frame and $\mathrm{T}$ represents the translation of the origin of the frame.

\section{Definition of mechanical behaviour of the assembly}

The behaviour of the assembly is known through the behaviour of each component and the links between components. Using a finite element method, the behaviour of links between components is known as the boundary conditions.

A link behaviour is defined by equations that represent the interface between two components expressed in terms of transmissible mechanical solicitation (contact 
is insured) and degrees of freedom (mechanical solicitation is null) as it is explained by Mounaud et al. (2007).

For each interface point, the equations result from:

- The mechanical equilibrium of the interface.

- The continuity of the displacement when contact is effective.

- The absence of mechanical solicitation when a degree of freedom exists.

- The stiffness of the interface when the interface is elastic.

As the values of the mechanical deviations are supposed to be known, the solution to the set of equations provides the values of the unknown in terms of displacements and mechanical solicitations.

\section{Calculation of Influence matrix based on the unit displacement method and part stiffness matrix from Finite Element Analysis}

A way of performing the simulation faster than solving the set of equations for each instance of geometry is to establish a linear relationship between part deviations and assembly spring-back deviations by using the Method of Influence Coefficient developed by Liu and $\mathrm{Hu}$ (1997). This method can be applied as part deviations from the nominal geometry are considered small and the material properties remain in the linear range.

In this method, a unit displacement is applied at the $i$-th source of variation, $\mathrm{i}=1$ to $6^{*} \mathrm{p}$, where $\mathrm{p}$ is the number of links. Then the set of equations is used to calculate the response $f_{i}$ under that unit displacement. $f_{i}$ represents a vector of influence coefficients associated to the $i$-th source of variation. If the response is recorded for all the sources of variation, the matrix of influence coefficients $\underline{\underline{S}}$ is obtained. As the mechanistic problem is considered a linear one, using the property of superposition of linear systems, the total imposed displacements $u_{d}$ of the tube can be expressed as a linear combination of unit displacements used for establishing matrix 


$$
f_{\text {tot }}=\underline{\underline{S}}^{*} u_{d}
$$

Consequently, all the installed forces $\mathrm{f}_{\text {tot }}$ (at each joint of the tube) can be calculated for all the configurations of the actual pipe geometry obtained with Monte Carlo simulations. As the assemblies studied are over-constrained, it is important to find an optimal datum choice to localize the actual tube's geometry.

\section{Identification of robust fixturing scheme}

To simulate the influence of the assembly sequence on the functional requirements the assembly has to satisfy, the first step is to find the most robust fixturing scheme. That consists in finding the best set of joints to minimize the geometrical deviations of the assembly. Each joint of a compliant part with others can be described as a combination of elementary joints i.e. point contact locator characterized by both its own point contact " $\mathrm{P}_{\mathrm{i}}$ " and its outward unit normal vector at contact point $\mathrm{n}_{\mathrm{ij}}$. ' $\mathrm{j}$ ' represents the elementary joint composing the $i$-th joint in case of same point contact.

To illustrate this, if a joint is considered a planar joint, it will be defined as a combination of 3 point locators in the same plane. For each point locator it is possible to define plückerian coordinates with equation 8:

$$
\left\{T_{p i}\right\}_{j}=\left\{\begin{array}{c}
n_{i j} \\
O P_{i} \times n_{i j}
\end{array}\right\}_{P_{i}}
$$

where $\mathrm{O}$ is a fixed point.

Deterministic localization is a fundamental requirement indicating that the part cannot make infinitesimal motion without losing contact with at least one locator. Some authors like Zhaoqing et al. (2008) use genetic algorithms to find the optimal fixture layout which sensitivity of product variation to fixture errors is minimized. The method proposed by Wang et al. (2001) allows to achieve this requirement only if a matrix called locator matrix, $M_{l o c}$ defined by equation 9 , has its full rank of 6 . 
The proposed locator matrix in this paper is composed of the plückerian coordinates of 6 elementary joints among all the possible elementary joints.

Please insert Figure 3

A classical 3-2-1 fixture scheme, represented on Figure 3, has its locator matrix with the following form:

$$
M_{\text {loc }}=\left(\left\{T_{P 1}\right\}_{1} \quad\left\{T_{P 2}\right\}_{1} \quad\left\{T_{P 3}\right\}_{1} \quad\left\{T_{P 4}\right\}_{1} \quad\left\{T_{P 5}\right\}_{1} \quad\left\{T_{P 6}\right\}_{1}\right)
$$

If there is a choice of 6 locators among $N$, at most $\mathbf{C}_{\mathbf{N}}^{6}=\frac{\mathbf{N} !}{6 !^{*}(\mathbf{N}-6) !}$ possible combinations to achieve this scheme exist. Maximizing the determinant of the locator matrix is a suitable criterion for accurate localization as shown by Wang and Pelinescu (2001) i.e. $\max \left(\left|\operatorname{det} M_{\text {loc }}\right|\right)$. As the method may be very time-consuming, a reduction of the combination can be achieved by avoiding wrong cases of localization. For example, if a fourth locator exists on the principal plan of figure 3 , there is a choice of 6 among 7 locators to make. Thus, solutions with 4 locators on the principal plan which over-constrain the layout of the part can be ruled out before the combinatory method.

\section{Simulation of assembly sequence}

A simulation of assembly sequence predicts more correlated results with physical tests than the FEA, based on the minimization energy principle detailed in section 3.2. Camelio et al. (2003) considered the assembly sequence as a multi-station assembly if it is assumed that a step of the assembly is represented as a station.

At each stage of the assembly, the equation (10) is equivalent to the following one:

$$
\left[\begin{array}{ll}
K & -l
\end{array}\right] *\left[\begin{array}{l}
u \\
f
\end{array}\right]=[0]
$$


Formally, force or displacement values can be imposed on every point leading to the boundary conditions. Writing all the boundary conditions leads to the equation 11:

$$
\left[\begin{array}{c}
K-I \\
\text { BoundaryConditions }
\end{array}\right] *\left[\begin{array}{l}
u \\
f
\end{array}\right]=\left[\begin{array}{c}
0 \\
S_{B C}
\end{array}\right]
$$

Considering that geometrical deviations are small and do not affect stiffness matrix coefficients, only the boundary conditions change while the assembly sequence proceeds. The propagation model of manufacturing variations, detailed in section 3.1, describes the gaps that must be compensated for when assembling the actual part on its joints. Only joints concerned at the current step of the assembly sequence are assembled. At each stage of the assembly sequence, boundary conditions have to meet the requirement set by the distance function defined below:

$$
d=d_{0}+d_{M_{P}}+d_{M_{f}}+d_{e f_{P}}+d_{e f_{f}}+d_{R B M}
$$

Where the different terms of the above equation are:

- $\mathrm{d}$ : actual distance between part and fixture

- $\mathrm{d}_{0}$ : nominal distance between part and fixture (=0 in case of assembly)

- $\mathrm{d}_{\mathrm{MP}}$ : Manufacturing deviation of the part

- $\mathrm{d}_{\mathrm{Mf}}$ : Manufacturing deviation of the fixture

- $\mathrm{d}_{\mathrm{efp}}$ : deformation of the part

- $\mathrm{d}_{\mathrm{eff}}$ : deformation of the fixture

- $\mathrm{d}_{\mathrm{RBM}}$ : rigid body motion if exists

The different distances can also be illustrated in the following Figure 4:

Please insert Figure 4

Although illustrations have been made in 1-D, as distances are defined as spatial vectors, 3-D problems can be solved thanks to this representation. As the actual distance between the part and the fixture has to be null to make an assembly, the boundary conditions can be solved. At a step of the assembly sequence, gaps of the considered joints thus constitute the boundary conditions the mechanistic problem 
has to take into account. Consequently, this displaces all the part geometry of the part at the beginning while the mechanism can have a rigid body motion. Once the part is totally constrained, from a kinematical point of view, its geometry deforms only under the applied displacements. The solution found at the $i$-th stage represents the gaps that need to be closed at the $i+1$-th stage. The method is iteratively going on until the end of the assembly sequence.

\section{Selection and representation of results}

The simulation of an assembly sequence is performed for instances of manufacturing deviations. The Monte Carlo method is used so that the results are representative of the real behaviour of the assembly. Synthetic representation has been chosen because the amount of available data is too important. Three representations of results are proposed. The first one provides an estimation of how the characteristics are respected, as shown in table 1.

Please Insert table 1

The global estimation of the conformity of the assemblies allows designers to validate the design or to modify the design if the rate of conformity in not acceptable. When this situation occurs, a two-dimensional or three-dimensional representation of the results of simulations is proposed.

Figure 5a illustrates a two dimensional representation of force distribution, the choice of the local projection plane is free. On the figure, the circle represents the admissible limit in term of force. Each point corresponds to the projection of a simulation result in the plane.

Please insert Figure 5a and Figure 5b 
As a complement to the previous representation, the distribution of any evaluated data is proposed and illustrated using a histogram (Figure 5b).

\section{Case Study}

The proposed method is illustrated trough an aeronautic example which consists in assembling a hydraulic tube on its brackets as shown on figure 6 . The metallic tube must satisfy the functional requirements in terms of geometrical deviations and limited effort in each joint. It is assumed that tube and brackets are compliant. The tube is fixed with 6 brackets on its route and 2 brackets on its extremities. Moreover, the joints are called Controlled Check Points (CCP). To position the tube, joints are thus considered as rotational joints for both ends and as sphere-cylinders in other cases. The main geometrical characteristics of the tube and its material properties are detailed in the following table 2 :

Please Insert table 2

Please Insert Figure 6 and table 3 (if possible)

The objective of the study is to simulate the assembly of the tube on a structure. The deviations on structure have already been evaluated and the machining process of the tube is known. At this stage of the design, the designer has to chose the technology of the brackets, to impose the assembly planning and to verify that the choices permit to respect the functional requirements on the assembly.

For a given choice of bracket technology, we propose to simulate the assembly of the pipe on the structure without taking into account the influence of assembly planning on specification fulfilments, This simulation is not time consuming and provides pertinent indicators about the assembly feasibility. Once the assembly 
feasibility is assumed, a more detailed study is performed to verify that functional requirements are respected while taking into account the influence of assembly planning.

We now propose to detail the seven steps of the method applied to the case study.

\section{Definition of each part deviations}

As mentioned above, deviations on the structure have already been evaluated. This previous study provides the dispersions of the positions of locating holes of the brackets relative to their nominal position. Locating holes appear to be centred on nominal position and the deviations respect a normal distribution. The structure is the base of the assembly, its frame $(\mathrm{O}, \mathrm{X}, \mathrm{Y}, \mathrm{Z})$ is the reference of the assembly.

Please insert table 4

In order to minimize both the mass and the machining cost of the six brackets, a unique technology has been chosen. The deviation of the position of the bracket centre, relative to its base, is defined in the frame associated to the bracket ( refer to table 5). Bracket deviations can thus be expressed in the frame of the structure.

Please Insert Figure 7 and table 5

Concerning the pipe, the manufacturing process (bending process) is known, and the capability of the bending process is identified. As shown in Mounaud et al. (2007), pipe geometry is classically represented as a sequence of elementary bending operations made with a forming die which radius is called $\mathrm{R}_{\mathrm{f}}$. These operations are characterized by L-R-A manufacturing coordinates, where L,R and A stand for 
Length between bends, Rotation between two successive bends and bent Angle, respectively, as shown in Figure 8.

Please Insert Figure 8

As a tube is made from a sequence of elementary operations, it is assumed that the geometry can be considered as a sequence of successive straight and circular elements. So local frames $\mathrm{R}_{\mathrm{i}}\left(\mathrm{P}_{\mathrm{i}}, \mathrm{X}_{\mathrm{i}}, \mathrm{Y}_{\mathrm{i}}, \mathrm{Z}_{\mathrm{i}}\right)$ can be associated with elementary elements i. Due to the manufacturing process, these coordinates $\left(\mathrm{L}_{\mathrm{i}}, \mathrm{R}_{\mathrm{i}}\right.$ and $\left.\mathrm{A}_{\mathrm{i}}\right)$ are made with deviations ( $d L_{i}, \mathrm{dR}_{\mathrm{i}}$ and $\mathrm{dA}_{\mathrm{i}}$ respectively) limited by the process capabilities $\mathrm{dL}, \mathrm{dR}$ and $\mathrm{dA}$ represented by the following constraint relations (equation 13, 14 and 15) for each actual elementary bending operation $\tilde{L}_{i}\left(\tilde{L}_{i}=L_{i}+d L_{i}\right), \tilde{R}_{i}\left(\tilde{R}_{i}=R_{i}+d R_{i}\right)$ and $\tilde{A}_{i}\left(\tilde{A}_{i}=A_{i}+d A_{i}\right)$ :

$$
\begin{aligned}
& L_{i}-\frac{d L}{2} \leq \tilde{L}_{i} \leq L_{i}+\frac{d L}{2} \\
& R_{i}-\frac{d R}{2} \leq \tilde{R}_{i} \leq R_{i}+\frac{d R}{2} \\
& A_{i}-\frac{d A}{2} \leq \tilde{A}_{i} \leq A_{i}+\frac{d A}{2}
\end{aligned}
$$

Figure 9 represents the distribution of the dL process capability. $\mathrm{dR}$ and $\mathrm{dA}$ are assumed having similar respresentations.

Please Insert Figure 9

The actual geometry of a pipe can easily be obtained by representing each elementary operation and its own defect with the Homogenous Transformation Matrix for L, R and A respectively: 


$$
\begin{aligned}
\mathbf{M}_{\mathbf{L}_{i}} & =\left(\begin{array}{llll}
1 & 0 & 0 & 0 \\
0 & 1 & 0 & \tilde{\mathrm{L}}_{\mathrm{i}} \\
0 & 0 & 1 & 0 \\
0 & 0 & 0 & 1
\end{array}\right)_{\mathbf{R}_{\mathrm{i}}} \\
\mathbf{M}_{\mathbf{R}_{\mathbf{i}}} & =\left(\begin{array}{cccc}
\cos \left(\tilde{\mathrm{R}}_{\mathrm{i}}\right) & 0 & \sin \left(\tilde{\mathrm{R}}_{\mathrm{i}}\right) & 0 \\
0 & 1 & 0 & 0 \\
-\sin \left(\tilde{\mathrm{R}}_{\mathrm{i}}\right) & 0 & \cos \left(\tilde{\mathrm{R}}_{\mathrm{i}}\right) & 0 \\
0 & 0 & 0 & 1
\end{array}\right)_{\mathbf{R}_{\mathrm{i}}} \\
\mathbf{M}_{\mathbf{A}_{\mathbf{i}}} & =\left(\begin{array}{cccc}
\cos \left(\tilde{\mathrm{A}}_{\mathrm{i}}\right) & -\sin \left(\tilde{\mathrm{A}}_{\mathrm{i}}\right) & 0 & \mathrm{R}_{\mathrm{fi}}{ }^{*}\left[1-\cos \left(\tilde{\mathrm{A}}_{\mathrm{i}}\right)\right] \\
\sin \left(\tilde{\mathrm{A}}_{\mathrm{i}}\right) & \cos \left(\tilde{\mathrm{A}}_{\mathrm{i}}\right) & 0 \\
0 & 0 & 1 \\
0 & 0 & 0 & 0 \\
\mathrm{R}_{\mathrm{fi}}{ }^{*} \sin \left(\tilde{\mathrm{A}}_{\mathrm{i}}\right) \\
0
\end{array}\right)_{\mathbf{R}_{\mathbf{i}}}
\end{aligned}
$$

$\mathrm{R}_{\mathrm{fi}}$ is the actual radius which integrates spring-back phenomenon as indicated in Lou and Stelson (2001). Thus, from the bend plan, the geometry of the actual tube may be generated in 3D-space by combining the effect of multiple bends through a series of matrix multiplications. As a consequence, in a global Cartesian coordinate system, the relative position $(\mathrm{Pi})$ of the different specific points $\left(\mathrm{P}_{\mathrm{iloc}}\right.$ in the local coordinate system of the elementary element i) of the tube is obtained with the following equation 16 :

$$
P i=\left(\prod_{k=1}^{k=i} M L_{k}{ }^{*} M R_{k}{ }^{*} M A_{k}\right){ }^{*} P_{i l o c}
$$

The bending process is characterized by the following values: $1 \mathrm{~mm}, 0.1^{\circ}$ and $1^{\circ}$ for $\mathrm{dL}, \mathrm{dR}$ and $\mathrm{dA}$ capabilities, respectively.

\section{Definition of the mechanical behaviour of each part}

The structure of the assembly is supposed to be rigid and the manufacturing deviations are known. As the structure is the base of the assembly, its frame $(\mathrm{O}, \mathrm{X}, \mathrm{Y}$, $\mathrm{Z}$ ) is the reference of the assembly (cf. Figure 7). 
The brackets 2 to 7 are considered as compliant with a linear model of deformation (5N.mm along axis in translation and 5Nm.rad along axis in rotation). The elementary stiffness matrix of a bracket is given equation 17 and 18:

$$
\begin{aligned}
& \underline{\underline{K}}^{j}=\left(\begin{array}{lll}
5 & 0 & 0 \\
0 & 5 & 0 \\
0 & 0 & 5
\end{array}\right)_{C C P_{i}, X_{i}, Y_{i}, Z_{i}} \\
& \underline{\underline{C}}^{j}=\left(\begin{array}{lll}
5 & 0 & 0 \\
0 & 5 & 0 \\
0 & 0 & 5
\end{array}\right)_{C C P_{i}, X_{i}, Y_{i}, Z_{i}}
\end{aligned}
$$

Moreover, it is assumed that extremities are considered as rigid $\mathrm{CCP}$

compared to brackets. So they are modelled with the elementary matrices in equation 17 and equation 18 where values of stiffness are respectively equal to 100 N.mm and 100 Nm.Rad. Considering the tube, the Finite Element Modelling used relies on a classical strength of material approach based on Bresses' equations. The model used is detailed explicitly in Mounaud et al. (2007). The simulation assumes that the tube deformation remains linear, that material behaviour is isotropic and that only small displacements are considered. The result of the Finite Element Modelling is the stiffness matrix of the tube.

\section{Definition of mechanical behaviour of the assembly}

The boundary conditions that permit to link the local behaviours of the components are now presented.

- For each interface between the structure and the brackets, the boundary condition is the continuity of displacement since contact is assured. Let $\mathrm{Si}$ be the point of the structure and $\mathrm{Bi}$ be the corresponding point of the bracket, then:

$\operatorname{Position}\left(B_{i}\right)=\operatorname{Position}\left(S_{i}\right)$

These equations 19 allow us to calculate the small displacement of the

considered bracket frame since the positioning of the bracket is equally constrained.

- For each interface point between the bracket and the pipe, the position of the actual bracket point is known since the small displacement of the bracket frame and the manufacturing deviation are known. The geometry of the tube is also 
available and then it is possible to calculate the value of the distance function presented in 3.6.

The technology of the bracket allows us to consider the link between the tube and the bracket as a sphere-cylinder link while the bracket is not clamped, and as a complete link when the bracket is clamped.

The boundary conditions associated to a complete link are the continuity of the displacement in all directions.

The boundary conditions associated to a sphere-cylinder link are:

- The continuity of the displacement along Yi and $\mathrm{Zi}$ directions.

- The absence of mechanical solicitation along axis where degrees of freedom exist (Xi direction in our case).

For each interface point, the remaining equations result from the mechanical equilibrium of the interface.

Calculation of Influence matrix based on the unit displacement method and part stiffness matrix from Finite Element Analysis

As the values of the mechanical deviations are supposed to be known, the solution to the whole set of equations provides the values of the unknown in terms of displacements and mechanical solicitations.

Using the method of the influence matrix, detailed in section 3.4, current assembly positions can be assessed and then the joint forces can be calculated at each step of the assembly sequence.

\section{Identification of the most robust fixturing scheme for part localization.}

The only component, for which the identification of the most robust fixturing scheme is needed, is the tube. The application of the method developed by Wang and Pelinescu (2001) to find the best fixturing scheme indicates that the tube is positioned with CCP 3, 6 and 7. The latter are called "positioning CCP" and the others, “clamping CCP”. 


\section{Simulation of an assembly sequence}

This step of the method only depends on the assembly sequences of clamping. For this case study, three sequences are studied as shown in table 6.

Please insert table 6

\section{Results}

For each sequence, 5000 simulations are performed using Monte Carlo method.

The indicators that result from sequence 1 simulations are presented in the table and indicate a global satisfaction of functional requirements, except for force criterion at point 1 and 8 and for displacements at point 2 .

\section{Please Insert Table 7}

Local representations of the forces and displacements at problematic points are presented in figure 10.

\section{Please insert figure 10}

From the local representations, we can conclude the global orientations of forces and displacements concerning points 1 and 2 and a homogeneous repartition concerning point 8 .

As the results of simulations are simplified, a more detailed analysis is proposed in order to quantify the influence of assembly planning. Two alternative assembly sequences are studied and the global results are presented in table 8 and 9 .

\section{Please Insert table 8}

Please Insert table 9

The global results in sequence 2 (Clamping Sequence CCP 26754 3) show a potential improvement in the fulfilment of functional requirements in terms of forces. 
Local results concerning efforts at point 1 and 8 and displacements at point 2 are proposed for this sequence analysis in figure 11.

Please insert Figure 11

The yield rate for the force requirement criterion is lower, so this assembly could be accepted concerning forces. The remaining problem concerns the displacements at point 2 . The influence of assembly planning is negligible and the yield rate is not acceptable.

At this stage of the design, bracket technology may still change. As the designer has effort and displacement repartitions at his disposal, he can take advantage of them to suggest a modification. Concerning point 2 where the problem occurs, we note in figure 12 that the range of displacement along $\mathrm{UZ}_{2}$ axis exceeds the limit, while the range of force along $\mathrm{UZ}_{2}$ axis does not reach the limit.

Please insert Figure 12

An increase in the stiffness of the bracket along $Z_{2}$ direction may increase forces and reduce displacements to produce an acceptable assembly design.

\section{Conclusion and future work}

Taking into account the assembly sequence of components in an aeronautic assembly contributes to the anticipation of the geometrical part deviations to verify that the deformed geometry meets functional requirements. The purpose of this paper is to present a model for the influence of assembly sequence which integrates manufacturing deviations for the fulfilment of product key characteristics. Part manufacturing deviations have been taken into account. Due to the assembly sequence of the structure parts, $\mathrm{CCP}$ positions present different variations along the different 
axes of the global frame. Moreover, the value of the variation can vary significantly from one $\mathrm{CCP}$ to another.

The proposed method is applied to piping assembly. As shown in section 4.1, the actual pipe geometry depends on bending process capabilities, so the impact of manufacturing deviations on tube geometry is easier simulated than with machining process for instance. Nevertheless, the method can be displayed on other instances of assembly since the inputs such as Stiffness Matrix, Key characteristics, process capabilities, joints scheme and models of joints behaviour are defined. Moreover, statistical tolerances with direct Monte Carlo simulation are employed, so computational time directly depends on the number of elements used in the simulations of manufacturing deviations.

Future extensions of this work include possibilities for adjustment solutions to be implemented in the early design stage. The proposed method can be used to compare different scenarii when multiple deviations occur. Last, the interaction of different technologic choices at the design stage can be investigated.

\section{Acknowledgements}

This research work has been carried out in the frame of the GRC-Flexible Assembly of the INNO'CAMPUS programme in partnership with EADS-IW. 


\section{References}

Ballot E., Bourdet P. and Thiébaut F., Determination of relative situations of parts for tolerance computation. Proc. of the $7^{\text {th }}$ CIRP Int. Sem. on Computer Aided Tolerancing, 2001, France, 65-74.

Breteau, P., Thiebaut F., Bourdet P. and Falgarone H., Assembly simulation of flexible parts through the fitting of linkage devices., Proc. of the $10^{\text {th }}$ CIRP Int. Sem. on Computer Aided Tolerancing, 2007, Germany.

Camelio, J., Hu, S.J. and Ceglarek, D., Modeling Variation Propagation of MultiStation Assembly Systems with compliant Parts. Trans. of ASME J. of Mech. Des., 2003, 125, 673-681.

Ceglarek, D.J. and Shi, J., Tolerance analysis for Sheet Metal Assembly using a Beam-Based Model. Trans. of ASME Int. Mech. Eng. Cong. and Exp., 1997, USA, 94, 153-159.

Chang, M. and Gossard D.C., Modeling the assembly of compliant, non-ideal parts. Computer Aided Design, 1997, 29, 701-708.

Cid, G., Thiebaut, F., Bourdet, P. and Falgarone, H., Geometrical study of assembly behaviour, taking into accounts rigid components' deviations, actual geometric variations and deformations. Proc. of the $9^{\text {th }}$ CIRP Int. Sem. on Computer Aided Tolerancing, 2005, USA, ISBN 1-4020-5437-8, 301-310.

Dahlström, S., Lindkvist, L. and Söderberg, R., Practical Implications in Tolerance Analysis of Sheet Metal Assemblies - Experiences from an Automotive Application., Proc. of the $9^{\text {th }}$ CIRP Int. Sem. on Computer Aided Tolerancing, 2005, USA, ISBN 1-4020-5437-8, 311-320.

$\mathrm{Hu}$, S.J., Camelio J., Arbor A., Modeling and Control for Compliant Assembly Systems. CIRP Annals - Manuf. Tech., 2006, 55, 19-22.

Huang, W., Lin, J., Kong, Z. and Ceglarek, D., Stream-of-Variation (SOVA) Modeling-Part II: A Generic 3D Variation Model for Rigid Body Assembly in Multistation Assembly Processes. Trans. of ASME J. of Manuf. Sc. and Eng., 2007, 129, 832-842.

Laperrière L., Ghie W. and Desrochers A., Statitiscal and deterministic Tolerance Analysis and Synthesis Using a Unified Jacobian-Torsor Model. CIRP Annals Manuf. Tech., 2002, 51, 417-420.

Laperriere, L. and Kabore T., Monte Carlo simulation of tolerance synthesis equations. Int. J. Prod. Res., 2001, 39, 2395-2406.

Liu, S. C. and Hu, S.J., Variation Simulation for Deformable Sheet Metal Assemblies Using Finite Element Methods. Trans. of ASME J. of Manuf. Sc. and Eng., 1997, 119, 368-374.

Loose, J.P., Zhou, Q., Zhou, S. and Ceglarek, D., Incorporation of GD\&T specifications into dimensional variation models for multistage machining processes. Int. J. Prod. Res., 2009, 47, Issue 10.

Lou, H. and Stelson, K. A., Three-dimensional tube geometry for rotary draw tube bending, Part 2: Statistical Tube Tolerance Analysis and Adaptive bend correction. Trans. of ASME J. of Manuf. Sc. and Eng., 2001, 123, 258-265.

Merkley, K.G., Tolerance analysis for compliant assemblies. Ph.D Thesis, 1998.

Mounaud, M., Thiebaut, F., Bourdet, P., Falgarone, H. and Chevassus N., Integrating the flexibility of components in the assembly of aeronautics hydraulic systems. Proc. of the $10^{\text {th }}$ CIRP Int. Sem. on Computer Aided Tolerancing, 2007, Germany. 
Pillet, M., Samper, S. and Formosa, F., Geometrical Inertial Tolerancing. $5^{\text {th }}$ Multidisciplinary Conf. on Quality and Dependability, 2005, France, 757-764.

Söderberg, R., Robust Design by Support of CAT Tools. Proc. of the ASME Design Automation Conf., 1998, USA, DETC98/DAC-5633.

Söderberg, R., Wickman, C. and Lindkvist L., Improving decision making by simulations and visualizing geometrical variation in non-rigid assemblies. CIRP Annals - Manuf. Tech., 2007, 57, 175-178.

Wang, Y.W. and Pelinescu, D.M., Optimizing Fixture Layout in a Point-Set Domain. IEEE Trans. on Rob. and Auto., 2001, 17, 312-323.

Wei, Y.F., Concurrent Design for Optimal Quality and Cycle Time. Ph.D Thesis, 2001, USA.

Wirtz A., Vectorial Tolerancing. Int. Conf. on CAD/CAM and AMT: CIRP Session on Tolerancing for function, 1998, 11-14.

Zhaoqing, T., Xinmin, L. and Zhongqin, L., Robust fixture layout design for multistation sheet metal assembly processes using a genetic algorithm. Int. J. Prod. Res., 2008. 


\begin{tabular}{|c|c|c|}
\hline $\mathrm{L}(\mathrm{mm})$ & $\mathrm{R}\left(^{\circ}\right)$ & $\mathrm{A}\left(^{\circ}\right)$ \\
\hline 54.85 & 0 & 90 \\
58.64 & -5.01 & 13.62 \\
164.93 & 180 & 13.62 \\
182.57 & 5.01 & 40.67 \\
87.14 & 0 & 49.33 \\
1387.80 & 26.41 & 50.14 \\
295.07 & -37.77 & 46.56 \\
72.75 & -25.46 & 48.28 \\
134.48 & -107.18 & 25.05 \\
100.51 & -15.64 & 35.61 \\
71.97 & 0 & 0 \\
\hline
\end{tabular}

\begin{tabular}{|l|c|}
\hline Outer diameter & $15.87 \mathrm{~mm}$ \\
\hline Thickness & $0.81 \mathrm{~mm}$ \\
\hline Material & Titan alloy \\
\hline Forming die & $50 \mathrm{~mm}$ \\
\hline
\end{tabular}

Table 2: Geometrical and mechanical characteristics of case study

Table 3: associated LRA manufacturing coordinates to case study

\begin{tabular}{|c|c|c|c|c|c|c|c|c|}
\hline & CCP1 & CCP2 & CCP3 & CCP4 & CCP5 & CCP6 & CCP7 & CCP8 \\
\hline X deviation & $0.5 \mathrm{~mm}$ & $0.5 \mathrm{~mm}$ & $0.25 \mathrm{~mm}$ & $0.25 \mathrm{~mm}$ & $0.25 \mathrm{~mm}$ & $0.25 \mathrm{~mm}$ & $0.25 \mathrm{~mm}$ & $0.25 \mathrm{~mm}$ \\
\hline Y deviation & $0.4 \mathrm{~mm}$ & $0.4 \mathrm{~mm}$ & $0.25 \mathrm{~mm}$ & $0.25 \mathrm{~mm}$ & $0.25 \mathrm{~mm}$ & $0.25 \mathrm{~mm}$ & $0.4 \mathrm{~mm}$ & $0.4 \mathrm{~mm}$ \\
\hline Z deviation & $0.25 \mathrm{~mm}$ & $0.25 \mathrm{~mm}$ & $0.4 \mathrm{~mm}$ & $0.4 \mathrm{~mm}$ & $0.4 \mathrm{~mm}$ & $0.4 \mathrm{~mm}$ & $0.25 \mathrm{~mm}$ & $0.25 \mathrm{~mm}$ \\
\hline
\end{tabular}

Table 4: Structure deviations on each CCP 


\begin{tabular}{|c|c|c|c|}
\hline Step & Sequence 1 & Sequence 2 & Sequence 3 \\
\hline 1 & Full tightening of CCP & Installation of positioning CCP (i.e. 3, 6 \& 7) \\
\hline 2 & Installation of all CCP & \multicolumn{2}{|c|}{ Installation of extremities } \\
\hline 3 & & \multicolumn{2}{|c|}{ Tightening of extremities } \\
\hline \multirow{2}{*}{4} & & \multicolumn{2}{|c|}{ Sequential positioning and tightening of remaining } \\
\cline { 3 - 4 } & & CCP following the sequence \\
\cline { 3 - 4 } & & CCP 3 6 7 4 52 & CCP 2 7 6 5 4 3 \\
\hline
\end{tabular}

Table 6: Assembly sequences simulated

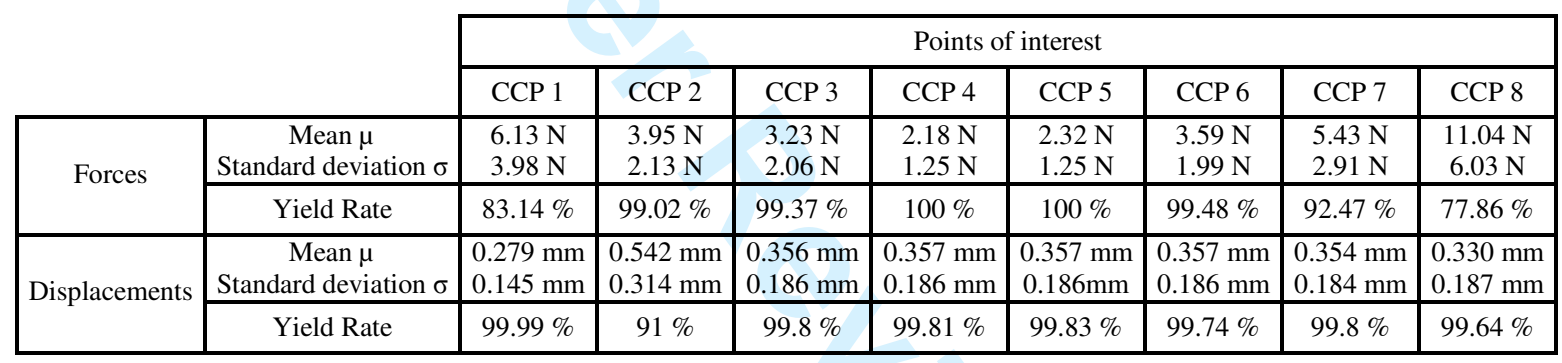

Table 7: Global results of tolerance analysis with no assembly sequence simulation

\begin{tabular}{|c|c|c|c|c|c|c|c|c|c|}
\hline & & \multicolumn{8}{|c|}{ Points of interest } \\
\hline & & CCP 1 & CCP 2 & CCР 3 & CCP 4 & CCP 5 & ССР 6 & CCP 7 & CCP 8 \\
\hline \multirow{2}{*}{ Forces } & $\begin{array}{c}\text { Mean } \mu \\
\text { Standard deviation } \sigma\end{array}$ & $\begin{array}{l}7.00 \mathrm{~N} \\
4.68 \mathrm{~N} \\
\end{array}$ & $\begin{array}{l}4.53 \mathrm{~N} \\
2.55 \mathrm{~N} \\
\end{array}$ & $\begin{array}{l}3.28 \mathrm{~N} \\
2.13 \mathrm{~N} \\
\end{array}$ & $\begin{array}{l}2.24 \mathrm{~N} \\
1.27 \mathrm{~N} \\
\end{array}$ & $\begin{array}{l}2.42 \mathrm{~N} \\
1.31 \mathrm{~N} \\
\end{array}$ & $\begin{array}{l}3.84 \mathrm{~N} \\
2.12 \mathrm{~N}\end{array}$ & $\begin{array}{l}5.38 \mathrm{~N} \\
2.88 \mathrm{~N}\end{array}$ & $\begin{array}{l}9.78 \mathrm{~N} \\
5.53 \mathrm{~N} \\
\end{array}$ \\
\hline & Rate of conformity & $77.84 \%$ & $96.56 \%$ & $99.06 \%$ & $100 \%$ & $100 \%$ & $99.06 \%$ & $91.38 \%$ & $79.25 \%$ \\
\hline \multirow{2}{*}{ Displacements } & $\begin{array}{c}\text { Mean } \mu \\
\text { Standard deviation } \sigma\end{array}$ & $\begin{array}{l}0.281 \mathrm{~mm} \\
0.146 \mathrm{~mm} \\
\end{array}$ & $\begin{array}{l}0.544 \mathrm{~mm} \\
0.321 \mathrm{~mm} \\
\end{array}$ & $\begin{array}{l}0.351 \mathrm{~mm} \\
0.183 \mathrm{~mm} \\
\end{array}$ & $\begin{array}{l}0.357 \mathrm{~mm} \\
0.188 \mathrm{~mm} \\
\end{array}$ & $\begin{array}{l}0.358 \mathrm{~mm} \\
0.188 \mathrm{~mm} \\
\end{array}$ & $\begin{array}{l}0.357 \mathrm{~mm} \\
0.184 \mathrm{~mm} \\
\end{array}$ & $\begin{array}{l}0.353 \mathrm{~mm} \\
0.183 \mathrm{~mm} \\
\end{array}$ & $\begin{array}{l}0.334 \mathrm{~mm} \\
0.190 \mathrm{~mm}\end{array}$ \\
\hline & Yield Rate & $100 \%$ & $90.56 \%$ & $99.8 \%$ & $99.78 \%$ & $99.82 \%$ & $99.82 \%$ & $99.84 \%$ & $99.68 \%$ \\
\hline
\end{tabular}

Table 8: Global results of tolerance analysis of assembly sequence 367542

\begin{tabular}{|c|c|c|c|c|c|c|c|c|c|}
\hline & \multicolumn{8}{|c|}{ Points of interest } \\
\hline & & CCP 1 & $\mathrm{CCP} 2$ & CCP 3 & СCР 4 & CCP 5 & ССР 6 & CCP 7 & ССР 8 \\
\hline \multirow{2}{*}{ Forces } & $\begin{array}{c}\text { Mean } \mu \\
\text { Standard deviation } \sigma\end{array}$ & $\begin{array}{l}5.81 \mathrm{~N} \\
3.66 \mathrm{~N} \\
\end{array}$ & $\begin{array}{l}3.95 \mathrm{~N} \\
2.16 \mathrm{~N} \\
\end{array}$ & $\begin{array}{l}3.36 \mathrm{~N} \\
2.14 \mathrm{~N} \\
\end{array}$ & $\begin{array}{l}2.25 \mathrm{~N} \\
1.3 \mathrm{~N} \\
\end{array}$ & $\begin{array}{l}2.42 \mathrm{~N} \\
1.31 \mathrm{~N} \\
\end{array}$ & $\begin{array}{l}3.82 \mathrm{~N} \\
2.09 \mathrm{~N} \\
\end{array}$ & $\begin{array}{l}5.38 \mathrm{~N} \\
2.84 \mathrm{~N} \\
\end{array}$ & $\begin{array}{r}10.60 \mathrm{~N} \\
6.00 \mathrm{~N} \\
\end{array}$ \\
\hline & Yield Rate & $87.66 \%$ & $99.06 \%$ & $99.1 \%$ & $100 \%$ & $100 \%$ & $99.1 \%$ & $92.9 \%$ & $83 \%$ \\
\hline \multirow{2}{*}{ Displacements } & $\begin{array}{c}\text { Mean } \mu \\
\text { Standard deviation } \sigma\end{array}$ & $\begin{array}{l}0.282 \mathrm{~mm} \\
0.147 \mathrm{~mm} \\
\end{array}$ & $\begin{array}{l}0.546 \mathrm{~mm} \\
0.320 \mathrm{~mm} \\
\end{array}$ & $\begin{array}{l}0.357 \mathrm{~mm} \\
0.187 \mathrm{~mm} \\
\end{array}$ & $\begin{array}{l}0.356 \mathrm{~mm} \\
0.185 \mathrm{~mm} \\
\end{array}$ & $\begin{array}{l}0.355 \mathrm{~mm} \\
0.186 \mathrm{~mm} \\
\end{array}$ & $\begin{array}{l}0.354 \mathrm{~mm} \\
0.184 \mathrm{~mm} \\
\end{array}$ & $\begin{array}{l}0.355 \mathrm{~mm} \\
0.183 \mathrm{~mm} \\
\end{array}$ & $\begin{array}{l}0.333 \mathrm{~mm} \\
0.191 \mathrm{~mm} \\
\end{array}$ \\
\hline & Yield Rate & $100 \%$ & $90.3 \%$ & $99.78 \%$ & $99.76 \%$ & $99.78 \%$ & $99.82 \%$ & $99.88 \%$ & $99.52 \%$ \\
\hline
\end{tabular}

Table 9: Global results of tolerance analysis of assembly sequence 267543 


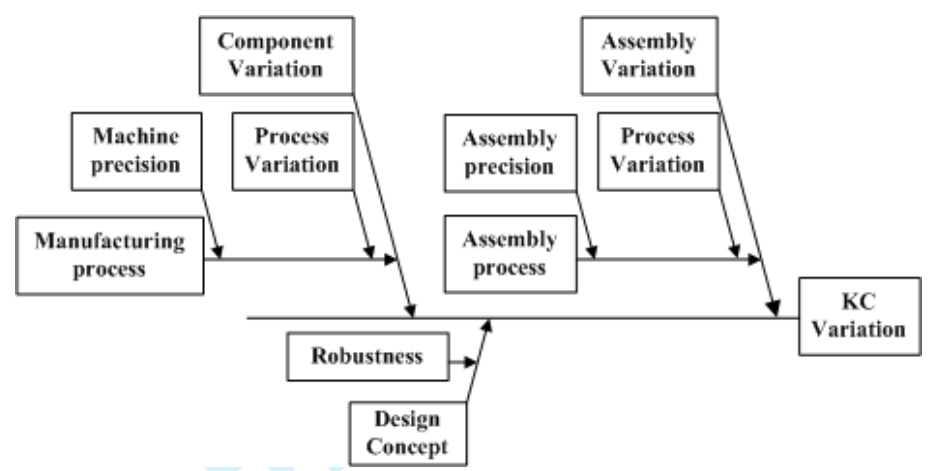

Figure 1: Geometrical KC variation contributors (Söderberg (1998))

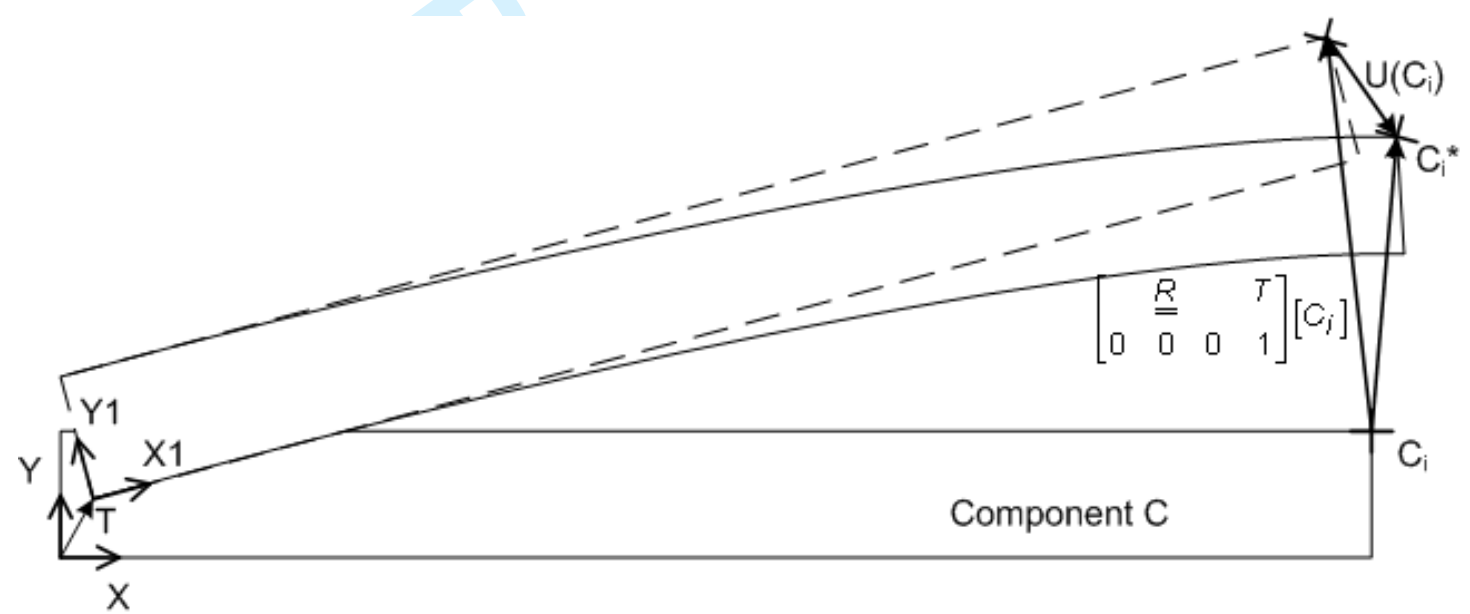

Figure 2: Displacement representation of a compliant component

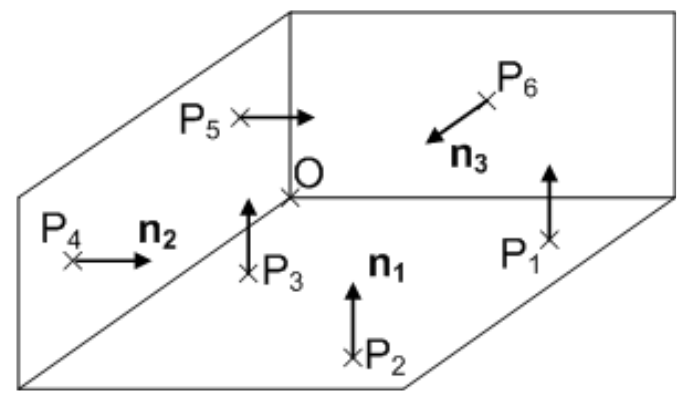

Figure 3 : classical 3-2-1 fixturing scheme 

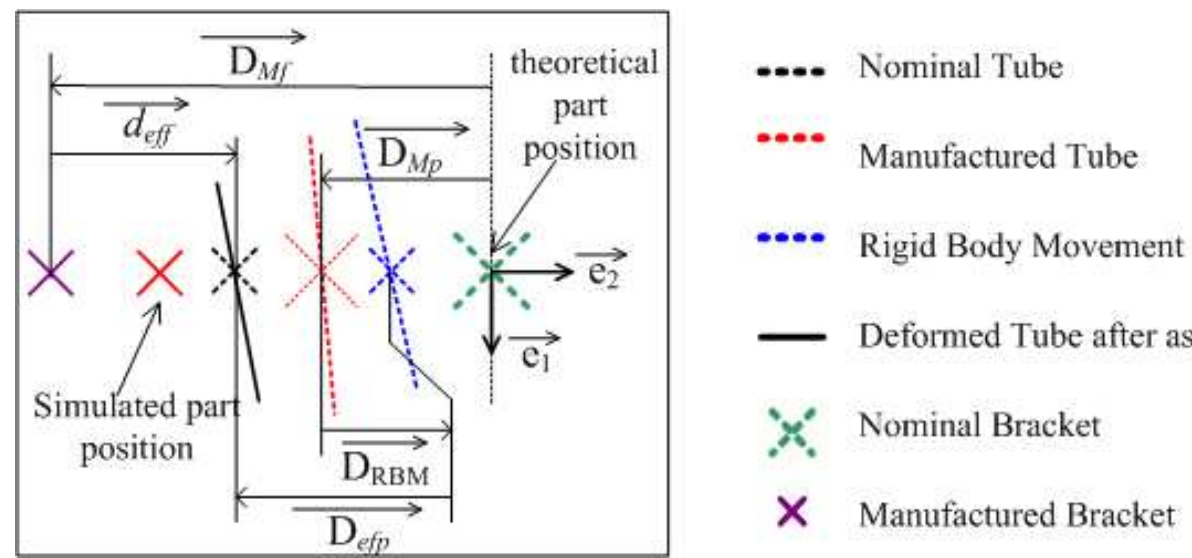

Figure 4: Assembly of an actual tube on actual brackets

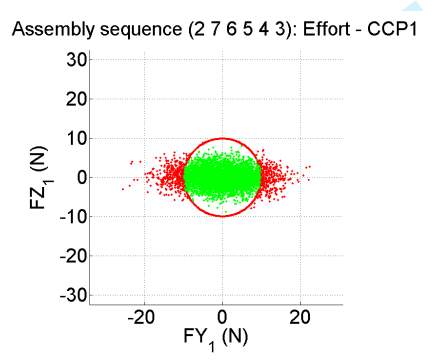

Figure 5a: synthetic graphical representation

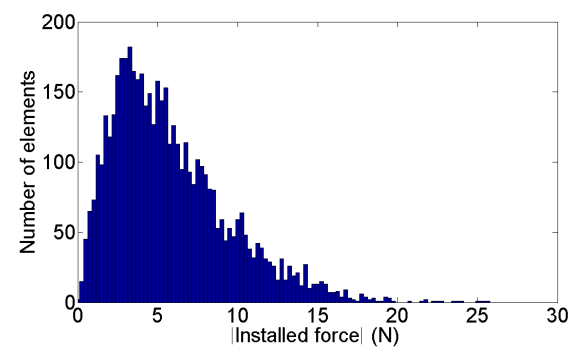

Figure 5b: histogram representation Figure 5: representation of force distribution 


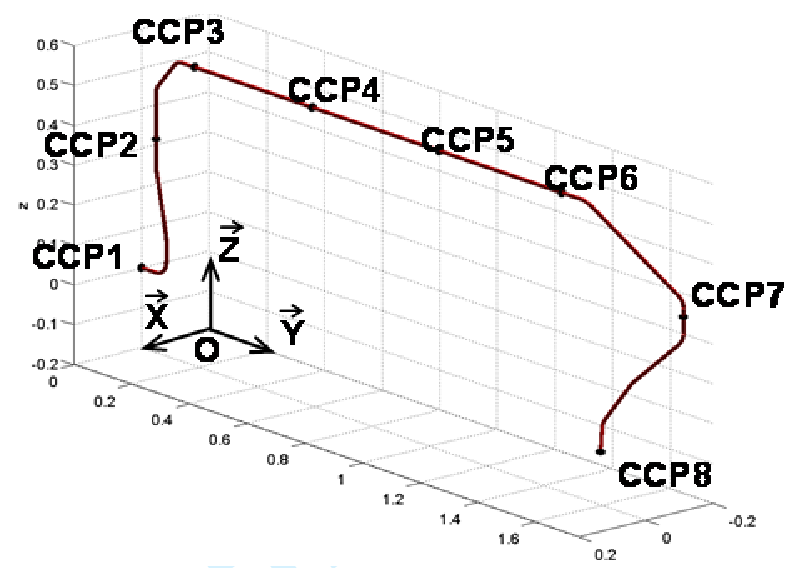

Figure 6: Case Study

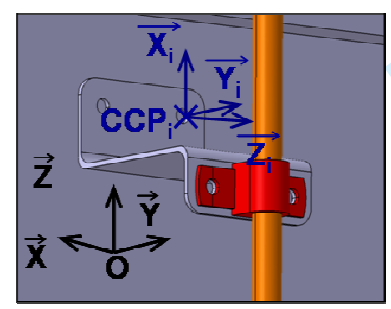

Figure 7: Bracket and structure frames

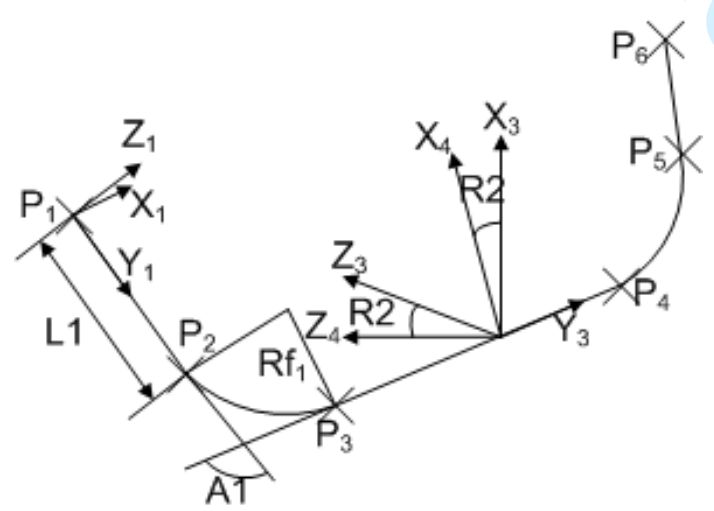

Figure 8: Manufacturing coordinates L, R, A

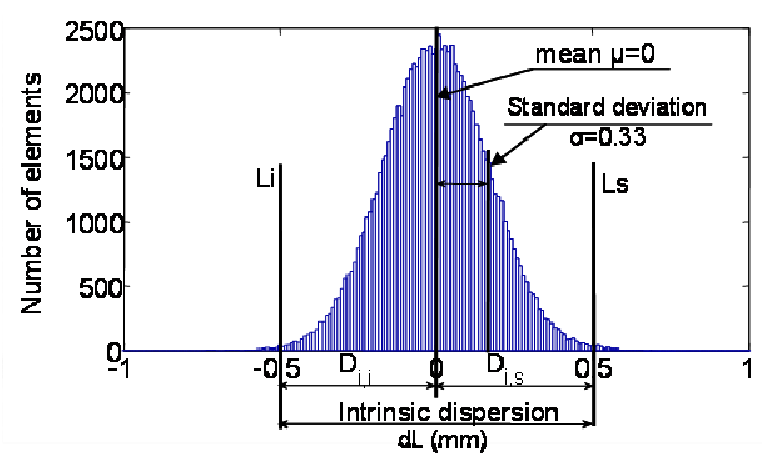

Figure 9: Intrinsic dL Bending process dispersion 

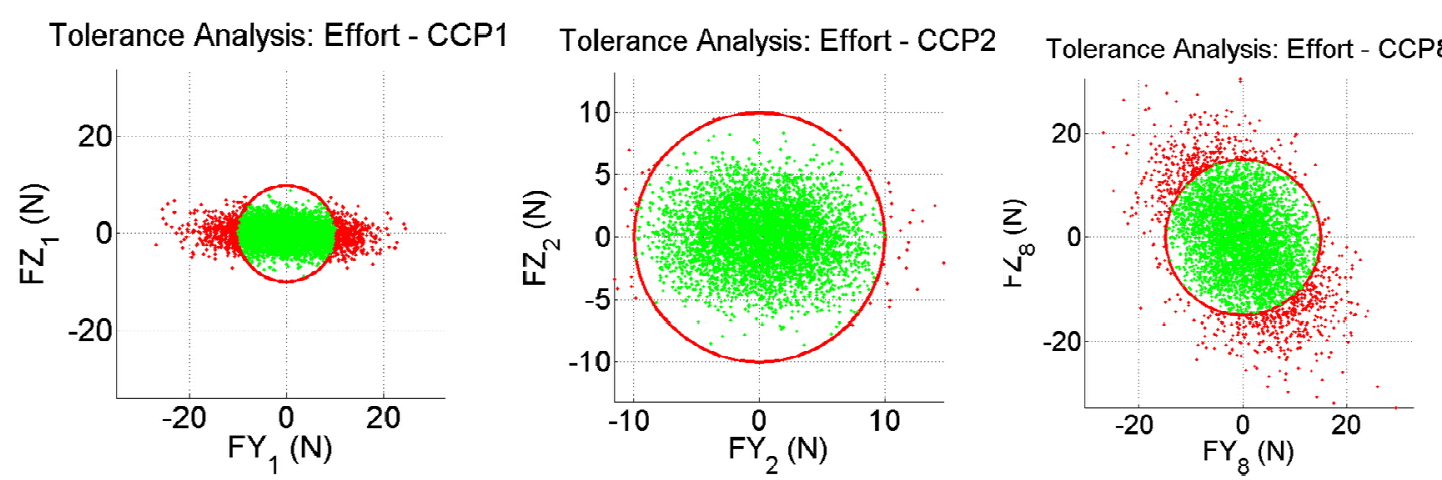

Figure 10: Local representations of the forces in CCP 1, CCP 2 and CCP 8 for Tolerance analysis

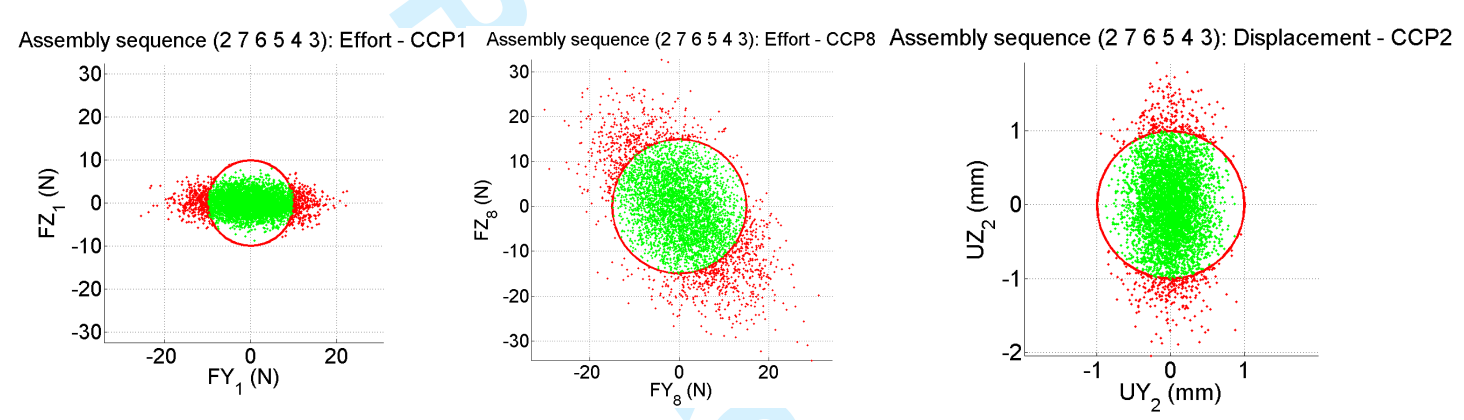

Figure 11: Local representations of the forces in CCP1 and CCP8 and displacement in CCP2 for assembly sequence 267543

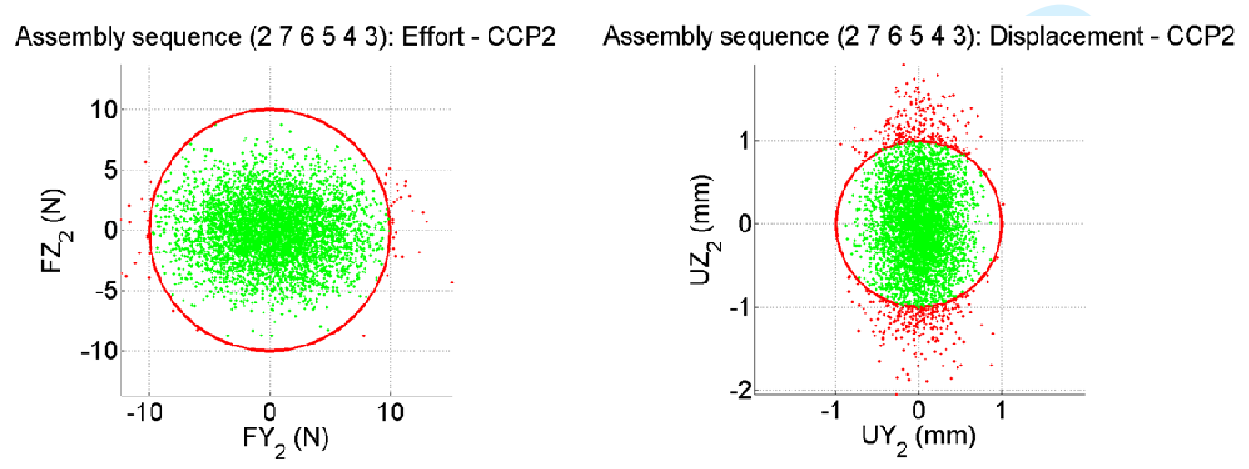

Figure 12: Local representations of the forces and displacements in CCP2 for assembly sequence 267543 